\title{
SARS-CoV-2 and lung transplantation. What do we know?
}

\author{
Corresponding author: \\ Kajetan Kiełbowski, Department \\ of Thoracic Surgery \\ and Transplantation, Pomeranian \\ Medical University, Szczecin, Poland \\ e-mail: kajetan.kielbowski@onet.pl
}

Medical Research Journal 2021; Volume 6, Number 2, 131-139 DOI: 10.5603/MRJ.2021.0025 Copyright @ 2021 Via Medica ISSN 2451-2591 e-ISSN 2451-4101

\begin{abstract}
Introduction: In 2019, new Coronavirus (SARS-CoV-2) has spread around the globe. The virus can replicate in the cells of the lower respiratory tract, causing pneumonia, oedema and hypoxia. In some patients, the disease will progress to acute respiratory distress syndrome (ARDS) which is a life-threatening condition. Lung transplantation (LuTx) might be the only rescue therapy for severe respiratory failure. Additionally, little is known about the impact of SARS-CoV-2 on lung transplant recipients. The purpose of this systematic review is to present current knowledge about lung transplantation as a treatment method for ARDS associated with COVID-19 infection and to summarize information regarding the management of COVID infection in lung transplant recipients.

Materials and methods: Literature search through different databases was conducted. Only case reports and case series were included.

Results: Out of 525 initial results, 16 studies were included in this systematic review. 7 articles presented patients with LuTx as a treatment option for ARDS and 9 presented management of lung recipients infected with COVID-19. A total of 37 patients were included in this systematic review.

Discussion: The course of reviewed patients with SARS-CoV-2 infection was similar and lung transplantation should be considered as a treatment of last chance when extracorporeal life support cannot be withdrawn. Further research is still required to assess the impact of new coronavirus on graft function in lung transplant recipients. Currently, the treatment strategy involves immunosuppression modification and supplemental oxygen therapy. However, some patients do not present clinical symptoms.

Key words: lung transplantation, coronavirus, COVID-19, ARDS
\end{abstract}

Med Res J 2021; 6 (2): 131-139

\section{Introduction}

Since December 2019, medical centers around the world have been struggling with the Covid-19 pandemic. The virus mainly affects the respiratory system; some patients may progress to acute respiratory distress syndrome (ARDS). Advanced age and comorbidities are considered as risk factors for severe disease. In $97 \%$ of the patients undergoing acute Covid-19 infection pathological changes in the chest are seen on CT images [1]. In case of irreversible and serious lung parenchyma damage, lung transplantation (LuTx) might be necessary to restore respiratory efficiency. LuTx is a treatment of the last chance performed in patients with end-stage lung diseases when conventional treatment does not provide improvement. According to the International Society of Heart and Lung Transplantation (ISHLT),
LuTx might be considered in patients with a 2-year mortality rate greater than $50 \%$ without transplant. Furthermore, a 5-year survival rate $>80 \%$ is required. In addition, this challenging surgery is associated with a long list of contraindications. For instance, the recent history of malignancy or dysfunction of another organ. Age over 65 years is a relative contraindication [2]. While LuTx is a life-saving surgery for patients with respiratory diseases, severe Covid-19 is associated with higher age and comorbidities that might prevent from becoming a potential candidate for transplantation [3]. There is a limited number of reports of LuTx performed due to Covid-related ARDS in the literature. Furthermore, the current SARS-CoV-2 pandemic represents a significant risk for lung transplant recipients. Little is known about the potential impact of the virus on graft function. Therefore, this systematic review presents 


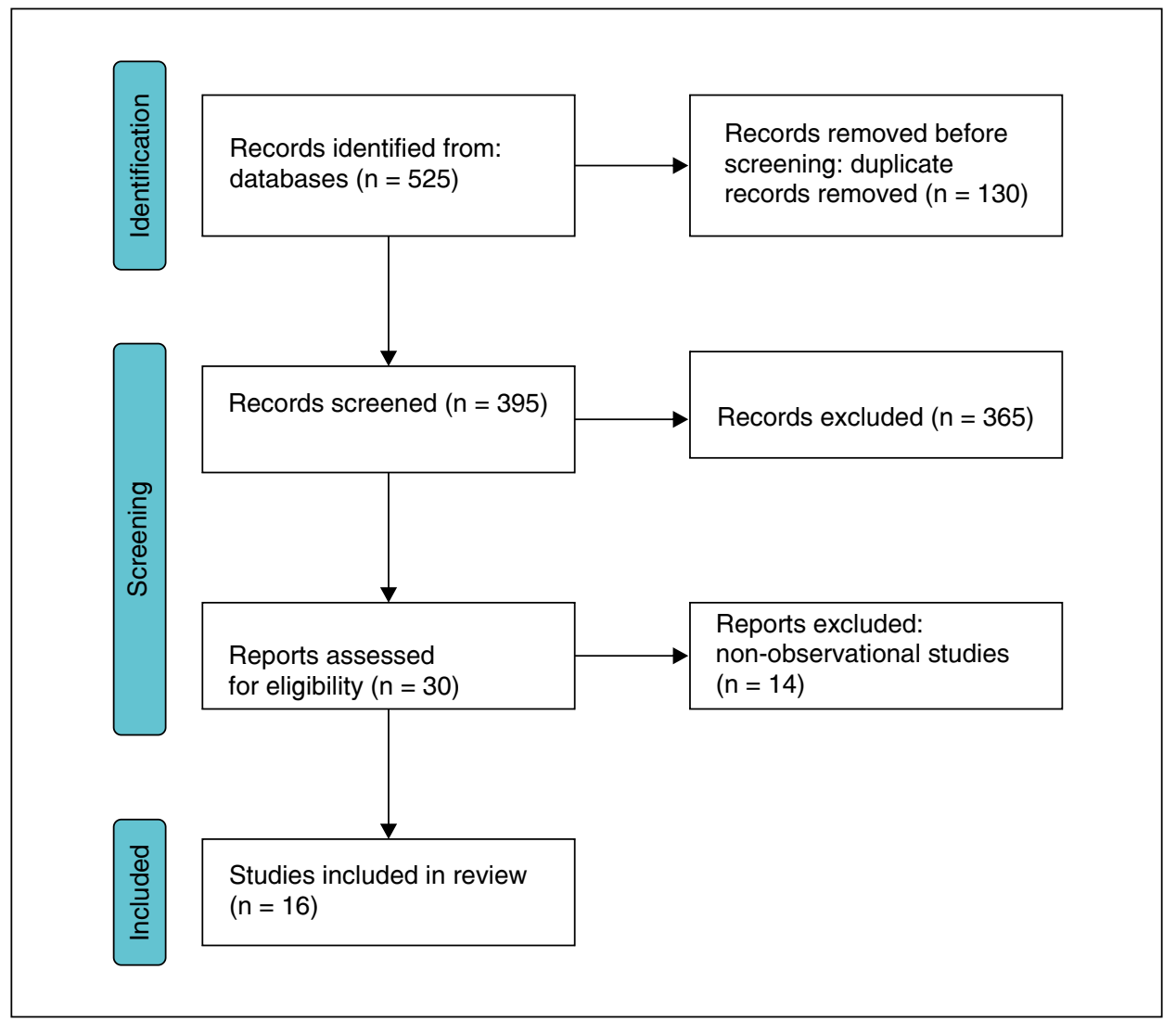

Figure 1. Flow diagram illustrating selection of the articles included in the systematic review

patients who underwent LuTx due to Covid-19 related ARDS and lung transplant recipients with postoperative Covid-19 infection. This systematic review aims to summarize current knowledge about SARS-CoV-2 infection that may lead to lung transplantation. Clinical features and management of patients progressed to ARDS are presented. Secondly, management of lung transplant recipients infected with Covid-19 is depicted as it may be beneficial for the development of future guidelines of postoperative care.

\section{Materials and methods}

This systematic review was conducted using PRISMA protocol (Preferred reporting items for systematic reviews and meta-analyses) [4]. Literature search through PubMed/Medline and Embase was performed. Flowchart representing search strategy is depicted in Figure 1. Phrases used for searching included: lung transplantation for Covid-19; lung transplant recipients Covid-19. Only case reports and case series written in English describing patients who underwent LuTx due to SARS-CoV-2 or lung transplant recipients with Covid-19 infection were included. 525 studies were identified after an initial search through databases. 395 studies' titles and abstracts were screened. After exclusion of non-observational studies and articles about transplantation of organs other than lungs, 30 studies remained for full-text assessment. 16 case reports and case series were ultimately included in this systematic review. Two reviewers independently screened titles and abstracts of studies chosen after primary search. Data was extracted manually from included studies. The second evaluation was performed in case of uncertainty. Characteristics (name of the first author, publication year, country, study design and infection status) of reviewed articles are presented in Table 1.

\section{Results}

7 articles presenting 13 cases of patients with ARDS were reviewed (Tab. 2). Mean age of presented patients was $54 \pm 8,7$ years. Presented cases included 4 females and 9 males. Some of the patients suffered from comorbidities like hypertension, diabetes or psoriasis, which might have contributed to the severe course of Covid-19. In all of the presented patients Extracorporeal 
Table 1. Characteristics of articled included in the systematic review

\begin{tabular}{lcccc}
\hline Author & Year & Country & Study / number of patients & COVID-19 infection \\
\hline Han W. [5] & 2020 & China & Case series / 2 & Before LuTx \\
Lang C. [6] & 2020 & Austria & Case report & Before LuTx \\
Chen J.Y. [7] & 2020 & China & Case series / 3 & Before LuTx \\
Bharat A. [8] & 2020 & USA & Case series / 3 & Before LuTx \\
Chen Y. [9] & 2021 & China & Case report & Before LuTx \\
Hu C. [10] & 2021 & China & Case report & Before LuTx \\
Croci G.A. [11] & 2021 & Italy & Case series / 2 & Before LuTx \\
Aigner C. [12] & 2020 & Germany & Case report & After LuTx \\
Koczulla R.A. [13] & 2020 & Germany & Case series / 2 & After LuTx \\
Morlacchi L.C. [14] & 2020 & Italy & Case series / 4 & After LuTx \\
Athanazio R.A. [15] & 2020 & Brazil & Case report & After LuTx \\
Cozzi E. [16] & 2020 & Italy & Case series / 2 & After LuTx \\
Raëth J. [17] & 2020 & France & Case report & After LuTx \\
Renaud-Picard B. [18] & 2020 & France & Case report & After LuTx \\
Verleden G.M. [19] & 2020 & Belgium & Case series / 10 & After LuTx \\
Desmazes-Dufeu N. [20] & 2021 & France & Case series / 2 & After LuTx \\
\hline
\end{tabular}

LuTx - lung transplantation

Membrane Oxygenation (ECMO) was applied due to respiratory failure. To support circulation for weeks, veno-venous ECMO had to be applied (bridge to LuTx), while veno-arterious ECMO was required intraoperatively. In 9 of reviewed cases, pulmonary artery hypertension (PAH) was observed. In the presented cases, mean time from Covid-19 confirmation to LuTx was $53,6 \pm 14$ days which shows how rapid the disease progression might be. Pathological examinations of resected lungs were similar. The mixture of fibrotic and necrotizing tissues was observed. Extensive consolidation and micro-thrombosis were found as well. In the majority of reviewed cases, large improvement was observed postoperatively. Extracorporeal life support has been withdrawn successfully days or weeks after LuTx while it was impossible prior to surgery. Lung function was mostly restored, and saturation was increased. Furthermore, patients regained independence in everyday activities. One death on postoperative day 1 was observed.

In addition, 9 case reports and case series with a total of 24 lung transplant recipients infected with COVID-19 were included (Tab. 3). Mean age of the patients was $51.5 \pm 6.7$ years. The mean time from LuTx to Covid-19 infection was $63.9 \pm 25.7$ months and the causes of LuTx included Chronic Obstructive Pulmonary Disease (COPD), Cystic Fibrosis (CF), non-specific interstitial pneumonia, pulmonary fibrosis, pulmonary hypertension, lymphangioleiomyomatosis and bronchiolitis obliterans syndrome after hematopoietic stem cell transplantation. Reviewed patients presented diversified symptoms. These included mild cold symptoms like fever, cough in some patients while others suffered from progressive dyspnea, malaise, hypoxia or thrombosis. In 13 patients ground-glass opacities in chest CT were observed. In 15 cases immunosuppression therapy was changed; cycle cell therapy was stopped (mycophenolate mofetil). In the vast majority of reviewed cases, antibacterial therapy was introduced, for instance, azithromycin, meropenem. In some patients, low molecular weight heparin was introduced. 3 patients had died ( 1 from multiorgan failure, 1 from graft injury caused by Covid-19 and bacterial infection, 1 from the deteriorated gas exchange).

\section{Discussion}

Coronaviruses are known for infections of the upper respiratory tract which cause mild symptoms. However, there are three viruses that replicate in the cells of the lower respiratory tract: Middle East respiratory syndrome coronavirus (MERS-CoV), Severe Acute Respiratory Syndrome Coronavirus (SARS-CoV) and SARS- 


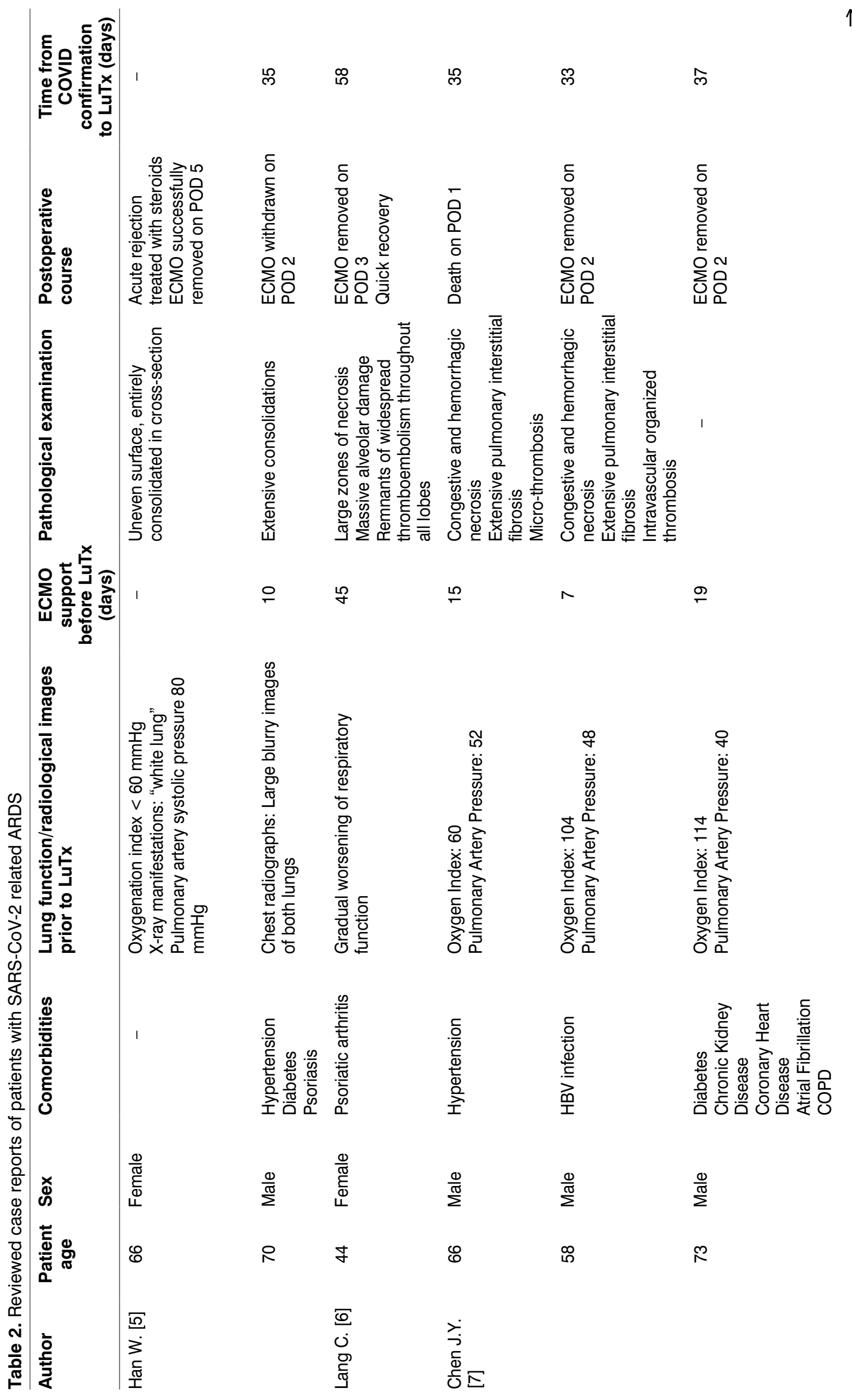




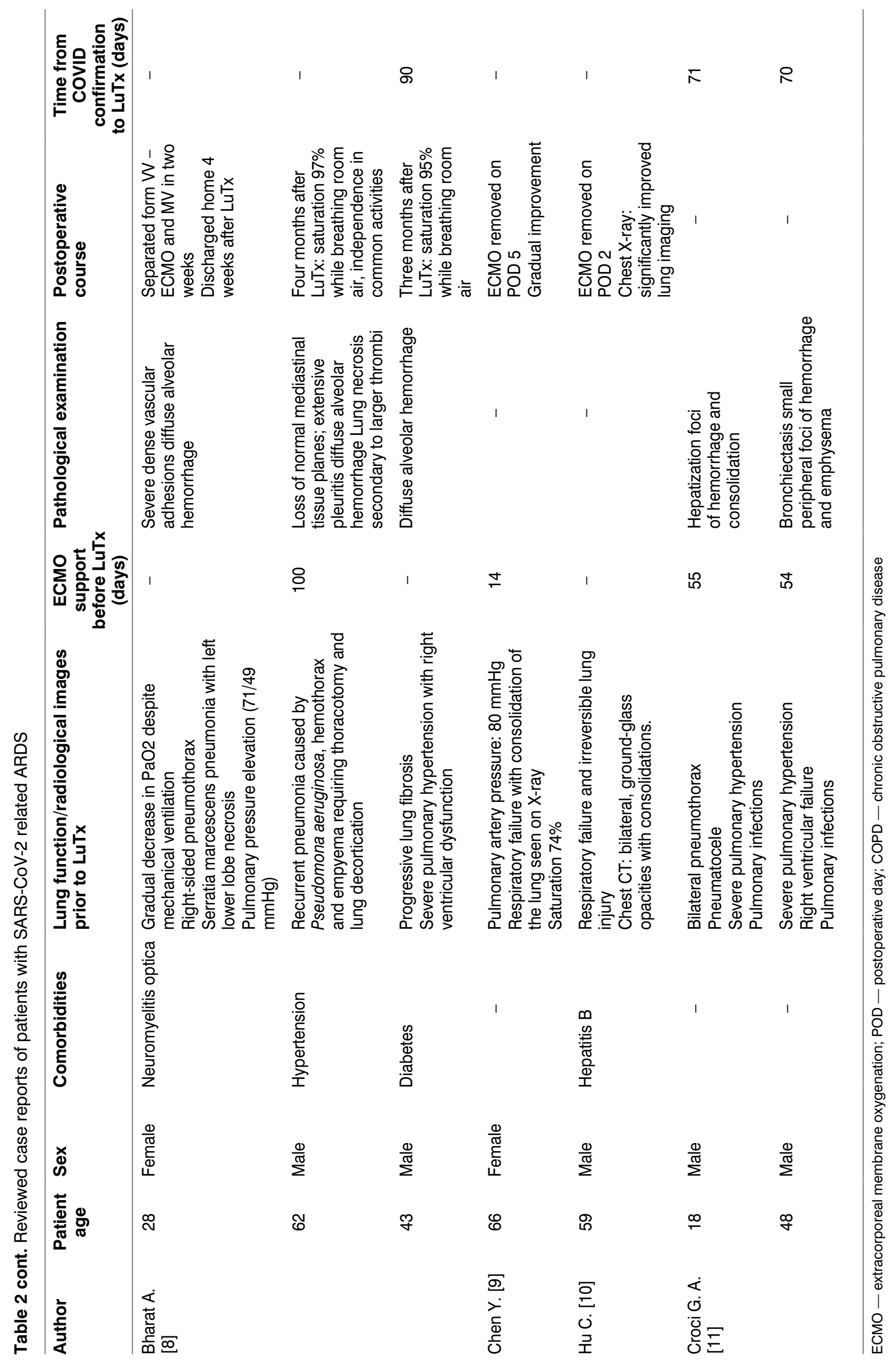


Table 3. Summary of the case reports and case series findings

\begin{tabular}{|c|c|c|}
\hline \multicolumn{2}{|l|}{ Variable } & $\begin{array}{l}\text { Number of patients/ } \\
\text { /number of studies }\end{array}$ \\
\hline \multicolumn{2}{|l|}{ Male } & $10 / 6$ \\
\hline \multicolumn{2}{|l|}{ Female } & $13 / 6$ \\
\hline \multicolumn{2}{|l|}{ Age $>65$ years } & $6 / 4$ \\
\hline \multicolumn{2}{|c|}{ Single lung transplantation } & $2 / 2$ \\
\hline \multicolumn{2}{|c|}{ Bilateral lung transplantation } & $19 / 7$ \\
\hline \multirow[t]{8}{*}{ Cause of LuTx } & Chronic obstructive pulmonary disease & $8 / 3$ \\
\hline & Cystic fibrosis & $7 / 6$ \\
\hline & Bronchiectasis & $2 / 1$ \\
\hline & Non-specific interstitial pneumonia & $1 / 1$ \\
\hline & Pulmonary fibrosis & $1 / 1$ \\
\hline & Pulmonary hypertension & $2 / 2$ \\
\hline & Pulmonary lymphangioleiomyomatosis & $1 / 1$ \\
\hline & Bronchiolitis obliterans after hematopoietic stem cell transplantation & $1 / 1$ \\
\hline \multicolumn{2}{|l|}{ Symptomatic } & $20 / 7$ \\
\hline \multicolumn{2}{|l|}{ Asymptomatic } & $3 / 3$ \\
\hline \multicolumn{2}{|c|}{ Ground-Glass opacities in CT } & $14 / 7$ \\
\hline \multicolumn{2}{|c|}{ CPAP/oxygen therapy/mechanical ventilation } & $13 / 6$ \\
\hline \multicolumn{2}{|c|}{ Immunosuppression modification } & $16 / 5$ \\
\hline \multicolumn{2}{|c|}{ Antibacterial therapy } & $21 / 7$ \\
\hline \multicolumn{2}{|l|}{ LMWH } & $5 / 3$ \\
\hline \multicolumn{2}{|l|}{ Death } & $3 / 3$ \\
\hline
\end{tabular}

CPAP — continuous positive airway pressure; LMWH - low molecular weight heparin

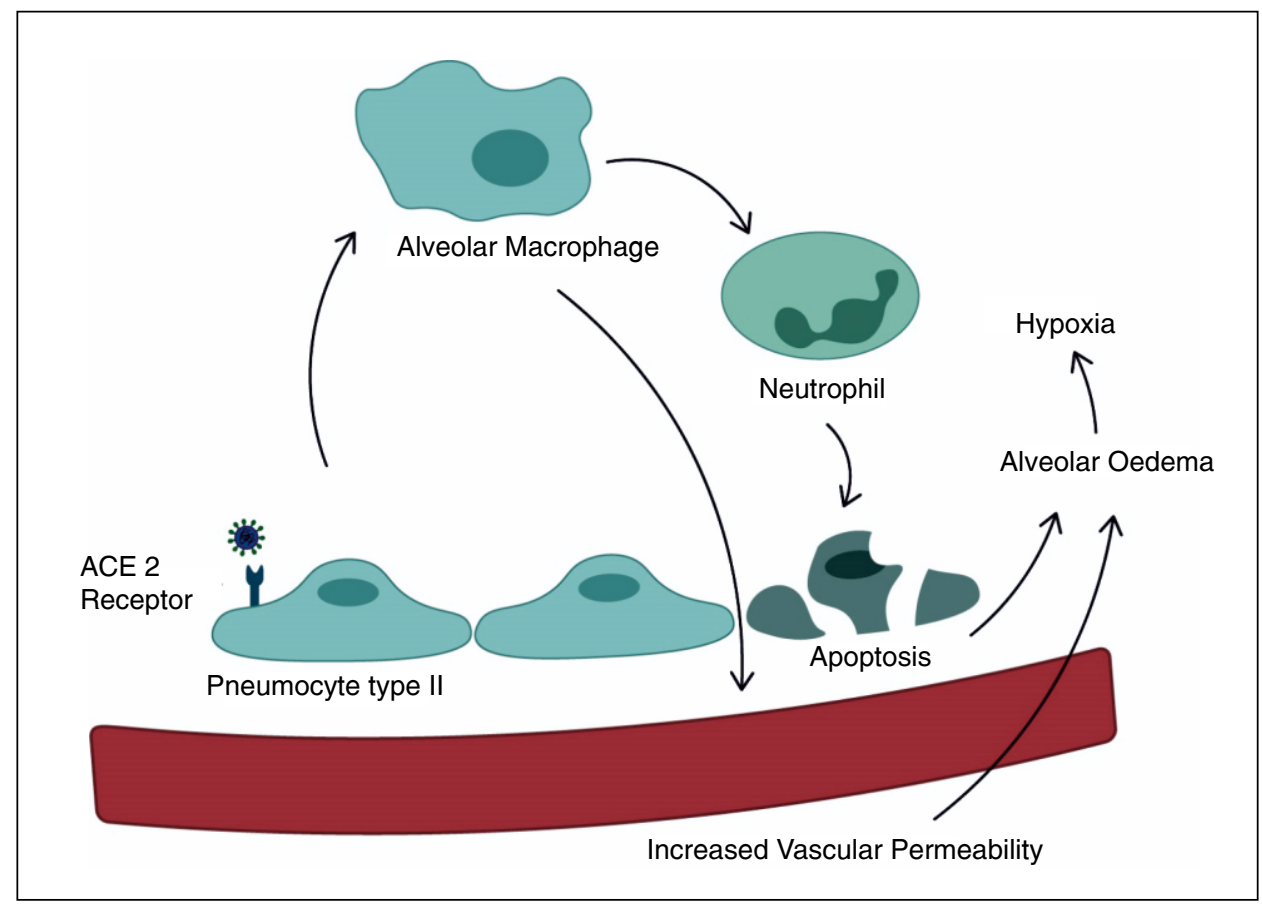

Figure 2. COVID-19 immunopathology 
CoV2 [21]. It is considered that the SARS-CoV-2 virus attacks all cells that express angiotensin-converting enzyme 2 receptor (ACE2) which is an entry receptor. Consequently, as the virus replicates its genome, the hosts immunology system is activated and proinflammatory cytokines are secreted. Alveolar macrophages stimulate vascular permeability and recruit neutrophils. Degranulation of these cells is responsible for pneumocytes and endothelial cells damage. Thus, these processes lead to alveolar oedema and hypoxia and are associated with the progressive development of ARDS (Fig. 2) [22]. Chronic inflammation and unsuccessful regeneration contribute to the development of pulmonary fibrosis, leading to damage of lung architecture. It is suggested that recruitment of myofibroblasts and alveolar epithelial damage are causes of most lung fibrosis processes [23]. In some of the reviewed cases, pathological examination revealed thrombosis of pulmonary vessels. Dysfunction of coagulation appears to be common in the course of Covid-19 infection. Vascular enlargement, which can be observed in chest CT, is frequently seen in Covid-19 patients while it is rarely reported in typical ARDS. Furthermore, Covid-19 related ARDS is associated with increased mortality rates compared to typical ARDS [24]. Respiratory failure due to ARDS is a life-threatening condition. In such cases, extracorporeal membrane oxygenation is a rescue therapy, and it was introduced in all of reviewed ARDS cases. Cannulation strategy for acute respiratory distress syndrome is a veno-venous ECMO, as it might support a patient for weeks. Furthermore, early use of VV-ECMO may reduce pulmonary inflammation and lower respiratory-driven pressure. Therefore, with its lung-protective mechanism, it is an accepted treatment for patients with ARDS [25]. However, if trials of ECMO removal are unsuccessful and patients condition does not seem to improve, lung transplantation might be the rescue therapy. However, during LuTx, veno-arterious ECMO should be applied, as VV-ECMO does not support cardiac function. In some patients, pulmonary artery hypertension (PAH) was observed. It is diagnosed when mean pulmonary arterial pressure is greater than $25 \mathrm{mmHg}$. $\mathrm{PAH}$ is associated with an increased risk of severe course of Covid and higher mortality rates [26].

In reviewed articles, the mean time of ECMO support prior to LuTx was 35,4 \pm 19 days. Mean time from COVID confirmation to LuTx was 53,6 \pm 14 days. In analysis performed by Chen J. et al. out of 249 patients, $8(3,2 \%)$ progressed to ARDS in $4.8 \pm 2.4$ days after the beginning of symptoms [27] which shows how rapid the disease progression to irreversible pulmonary damage may be.

It is unclear how SARS-CoV-2 infection affects lung transplant recipients and graft function. In reviewed articles, the course of infection varied among patients. In the majority of reviewed articles, patients presented fever, cough, dyspnea or hypoxia. However, three patients underwent Covid-19 infection without clinical symptoms. A total of 13 patients required supplemental oxygen therapy, mechanical ventilation or continuous positive airway pressure (CPAP). Together with noninvasive ventilation, CPAP is introduced in patients with hypoxemic respiratory failure as a result of pulmonary oedema. Due to the lack of randomized control trials, there are no recommendations for using CPAP in viral infections. According to a retrospective review performed by Brusasco C. et al. 64 patients were supported with CPAP due to Covid-19 respiratory failure. Criteria for CPAP application were: $\mathrm{PaO}_{2} / \mathrm{FIO}_{2}<200$, $\mathrm{PaO}_{2}<60 \mathrm{mmHg}$, breathing frequency $>30 \mathrm{~min}$ and dyspnea at rest. The majority of patients recovered after the use of CPAP $(n=53)$ and were discharged from the hospital within 28 days [28]. In large number of patients chest CT revealed ground-glass opacities (GGOs). Chest CT is a significant tool in COVID diagnosis due to its high sensitivity. Replicating virus in alveolar epithelium and damage of epithelial surface (leakage) manifest as GGOs. Other changes involve vascular enlargement, consolidation and bronchial wall thickening. These changes usually occur bilaterally [29]. According to a systematic review performed by Salehi S. et. al GGOs may be observed in the early stage of infection (1-2 weeks after exposure). Furthermore, these changes may be observed despite negative COVID-19 PCR results [30]. Thus, chest CT could be beneficial to identify the early stage of coronavirus infection in lung transplant recipients. Immunosuppression therapy for lung recipients consists of three elements: calcineurin inhibitors (tacrolimus), cycle cell inhibitors (mycophenolate mofetil) and corticosteroids. In reviewed cases, mycophenolate was reduced or stopped during infection. This approach was also undertaken by Pereira M.R. et al. in solid organ transplant recipients with Covid-19 [31]. Elevation of proinflammatory cytokines (IL-6, TNF) was observed in patients with severe course of SARS-CoV infection. Those are involved in abnormal clot formation leading to the development of thrombosis. Thus, low molecular weight heparin (LMWH) should be considered to prevent deep vein thrombosis or clot formation in pulmonary vessels. Among reviewed cases, 5 patients were treated with LMWH [32]. According to analysis performed by Coll E. et al., who reviewed 778 solid organ and haemopoietic stem cell transplant recipients, lung transplant recipients $(n=54)$ had a significantly higher risk of death (OR: $2.595 \% \mathrm{Cl}$ : 1.4-4.6). Furthermore, the course of infection was more aggressive compared to recipients of other organs which may be related to more potent immunosuppression and poorer respiratory reserve [33]. According to a report written by 
Messika J et. al, among 35 lung recipients, 31 (88,6\%) required hospitalization due to Covid-19 infection. The presentation was mostly severe, while 5 patients died due to Covid-19 infection [34]. The early phase of the Covid-19 pandemic reduced the number of lung transplantations performed [35]. Consequently, more patients are on the waiting list and more deaths among those patients has occurred [36]. This systematic review should be considered with several limitations. Firstly, despite a comprehensive search of available studies, some upcoming articles could have been missed due to evolving nature of Covid-19. Secondly, some cases of lung transplant recipients could have been described in studies summarizing recipients of other organs as well, not meeting the inclusion criteria for this review. These factors might be responsible for introducing a bias.

\section{Conclusions}

The global pandemic proved to be a critical challenge for healthcare systems and physicians. Lung damage caused by SARS-CoV-2 may be thorough and irreversible. Supplemental oxygen therapy or ventilation is used to support patients in worsening conditions.

However, if the deterioration of lung function progresses, extracorporeal membrane oxygenation might be a rescue therapy. Failure in ECMO withdrawal indicates that lung transplantation is required. As seen in reviewed cases, LuTx provided an improvement and ECMO could be withdrawn few days after the surgery. Therefore, Covid-19 related ARDS might be treated, and mortality rates lowered. However, with limited access to extracorporeal circulatory support devices and an increasing number of Covid-19 patients with ARDS due to ongoing pandemic, this treatment strategy may be approachable only in certain patients. Performing LuTx in patients with severe ARDS associated with Covid-19 is extremely challenging as there are not any official guidelines. Furthermore, the surgery itself is a very invasive treatment. Additional use of extracorporeal life support increases the risk of other serious complications like acute kidney injury, bleeding or thromboembolic complications. Coronavirus pandemic introduced obstacles that have not been previously encountered. For instance, testing donor's lungs for Covid-19; providing surgical facilities with adequate protection level or wearing virus protection suits by the surgical team. In addition, little is known about the potential impact of Covid-19 on lung transplant recipients and further research is required to develop adequate guidelines of postoperative care. We strongly believe that this review may be beneficial as it promotes lung transplantation as a treatment of the last chance in case of patients who progressed to ARDS due to Covid-19 infection.
Furthermore, a summary of treatment methods and management of infected lung transplant recipients may be helpful in developing future guidelines.

\section{References}

1. Czajkowska-Malinowska M, Kania A, Kuca PJ, et al. Treatment of acute respiratory failure in the course of COVID-19. Practical hints from the expert panel of the Assembly of Intensive Care and Rehabilitation of the Polish Respiratory Society. Adv Respir Med. 2020; 88(3): 245-266, doi: 10.5603/ARM.2020.0109, indexed in Pubmed: 32706108.

2. Weill $D$, Benden $C$, Corris PA, et al. A consensus document for the selection of lung transplant candidates: 2014--an update from the Pulmonary Transplantation Council of the International Society for Heart and Lung Transplantation. J Heart Lung Transplant. 2015; 34(1): 1-15, doi: 10.1016/j.healun.2014.06.014, indexed in Pubmed: 25085497.

3. Cypel M, Keshavjee S. When to consider lung transplantation for COVID-19. The Lancet Respiratory Medicine. 2020; 8(10): 944-946, doi: 10.1016/s2213-2600(20)30393-3.

4. Moher D, Liberati A, Tetzlaff J, et al. PRISMA Group. Preferred reporting items for systematic reviews and meta-analyses: the PRISMA statement. PLoS Med. 2009; 6(7): e1000097, doi: 10.1371/journal. pmed.1000097, indexed in Pubmed: 19621072.

5. Han W, Zhu M, Chen J, et al. Lung transplantation for elderly patients with end-stage COVID-19 pneumonia. Ann Surg. 2020; 272(1): e33-e34, doi: 10.1097/SLA.0000000000003955, indexed in Pubmed: 32301803.

6. Lang C, Jaksch P, Hoda M, et al. Lung transplantation for COVID-19-associated acute respiratory distress syndrome in a PCR-positive patient. The Lancet Respiratory Medicine. 2020; 8(10): 1057-1060, doi: 10.1016/s2213-2600(20)30361-1.

7. Chen JY, Qiao K, Liu F, et al. Lung transplantation as therapeutic option in acute respiratory distress syndrome for coronavirus disease 2019-related pulmonary fibrosis. Chin Med J (Engl). 2020; 133(12): 1390-1396, doi: 10.1097/CM9.0000000000000839, indexed in Pubmed: 32251003.

8. Bharat A, Querrey M, Markov NS, et al. Lung transplantation for patients with severe COVID-19. Sci TransI Med. 2020; 12(574), doi: 10.1126/scitranslmed.abe4282, indexed in Pubmed: 33257409.

9. Chen $\mathrm{Y}$, Wang $\mathrm{H}$, Mou $\mathrm{Y}$, et al. Peri-operative echocardiography for lung transplantation in a critical patient with COVID-19. Cardiovasc J Afr. 2021 [Epub ahead of print]; 32: 1-3, doi: 10.5830/CVJA-2020064, indexed in Pubmed: 33496722.

10. Hu C, Wang G, Zhou D, et al. The anesthetic management of the first lung transplant for a patient with COVID-19 respiratory failure. J Cardiothorac Vasc Anesth. 2021; 35(3): 917-920, doi: 10.1053/j. jvca.2020.06.011, indexed in Pubmed: 32653268.

11. Croci GA, Vaira V, Trabattoni D, et al. Emergency lung transplantation after COVID-19: immunopathological insights on two affected patients. Cells. 2021; 10(3), doi: 10.3390/cells10030611, indexed in Pubmed: 33801959

12. Aigner $\mathrm{C}$, Dittmer U, Kamler M, et al. COVID-19 in a lung transplant recipient. J Heart Lung Transplant. 2020; 39(6): 610-611, doi: 10.1016/j. healun.2020.04.004, indexed in Pubmed: 32340870.

13. Koczulla RA, Sczepanski B, Koteczki A, et al. SARS-CoV-2 infection in two patients following recent lung transplantation. Am J Transplant. 2020; 20(10): 2928-2932, doi: 10.1111/ait.15998, indexed in Pubmed: 32400084.

14. Morlacchi LC, Rossetti $\bigvee$, Gigli L, et al. COVID-19 in lung transplant recipients: A case series from Milan, Italy. Transpl Infect Dis. 2020; 22(6): e13356, doi: 10.1111/tid.13356, indexed in Pubmed: 32510771.

15. Athanazio RA, Costa AN, Carraro RM, et al. Early COVID-19 infection after lung transplantation in a patient with cystic fibrosis. Clinics (Sao Paulo). 2020; 75: e2274, doi: 10.6061/clinics/2020/e2274, indexed in Pubmed: 33263634

16. Cozzi E, Faccioli E, Marinello S, et al. COVID-19 pneumonia in lung transplant recipients: Report of 2 cases. Am J Transplant. 2020; 20(10): 2933-2937, doi: 10.1111/ajt.15993, indexed in Pubmed: 32400074.

17. Raëth J, Tomio A, Eugene A, et al. Immunosuppression in a lung transplant recipient with COVID-19? Lessons from an early case. Respir Med Res. 2020; 78: 100782, doi: 10.1016/j.resmer.2020.100782, indexed in Pubmed: 32801101

18. Renaud-Picard B, Gallais F, Ohana M, et al. Bilateral acute cardioembolic limb ischemia after Coronavirus disease 2019 pneumonia in a lung transplant recipient: A case report. Transplant Proc. 2020; 52(9): 2715-2718, doi: 10.1016/j.transproceed.2020.06.024, indexed in Pubmed: 32713821 
19. Verleden GM, Godinas L, Lorent N, et al. COVID-19 in lung transplant patients: A case series. Am J Transplant. 2020; 20(11): 3234-3238, doi: 10.1111/ajt.16212, indexed in Pubmed: 32659857.

20. Desmazes-Dufeu N, Coltey B, Amari L, et al. Discordant courses of COVID-19 in a cohabiting couple of lung transplant recipients. Transpl Infect Dis. 2021; 23(1): e13410, doi: 10.1111/tid.13410, indexed in Pubmed: 32654244.

21. Tay MZ, Poh CM, Rénia L, et al. The trinity of COVID-19: immunity, inflammation and intervention. Nat Rev Immunol. 2020; 20(6): 363-374 doi: 10.1038/s41577-020-0311-8, indexed in Pubmed: 32346093

22. Batah SS, Fabro AT. Pulmonary pathology of ARDS in COVID-19: A pathological review for clinicians. Respir Med. 2021; 176: 106239 doi: 10.1016/j.rmed.2020.106239, indexed in Pubmed: 33246294.

23. Lechowicz K, Drożdżal S, Machaj F, et al. COVID-19: the potentia treatment of pulmonary fibrosis associated with SARS-CoV-2 infection. J Clin Med. 2020; 9(6), doi: 10.3390/jcm9061917, indexed in Pubmed: 32575380

24. Gibson PG, Qin L, Puah SH. COVID-19 acute respiratory distress syndrome (ARDS): clinical features and differences from typical pre-COVID-19 ARDS. Med J Aust. 2020; 213(2): 54-56.e1, doi: 10.5694/mja2.50674, indexed in Pubmed: 32572965

25. Kowalewski M, Fina D, Słomka A, et al. COVID-19 and ECMO: the interplay between coagulation and inflammation-a narrative review. Crit Care. 2020; 24(1): 205, doi: 10.1186/s13054-020-02925-3, indexed in Pubmed: 32384917.

26. Sulica R, Cefali F, Motschwiller C, et al. COVID-19 in pulmonary artery hypertension (PAH) patients: observations from a large PAH center in New York City. Diagnostics (Basel). 2021; 11(1), doi: 10.3390/diagnostics11010128, indexed in Pubmed: 33467533

27. Chen J, Qi T, Liu Li, et al. Clinical progression of patients with COVID-19 in Shanghai, China. J Infect. 2020; 80(5): e1-e6, doi: 10.1016/j. jinf.2020.03.004, indexed in Pubmed: 32171869.

28. Brusasco C, Corradi F, Di Domenico A, et al. Galliera CPAP-Covid-19 study group, collaborators of the Galliera CPAP-COVID-19 study group are. Continuous positive airway pressure in COVID-19 patients with moderate-to-severe respiratory failure. Eur Respir J. 2021; 57(2) doi: 10.1183/13993003.02524-2020, indexed in Pubmed: 33033151

29. Zheng $Y$, Wang L, Ben S. Meta-analysis of chest CT features of patients with COVID-19 pneumonia. J Med Virol. 2021; 93(1): 241-249, doi: 10.1002/jmv.26218, indexed in Pubmed: 32579236.

30. Salehi S, Abedi A, Balakrishnan S, et al. Coronavirus disease 2019 (COVID-19): A systematic review of imaging findings in 919 patients. AJR Am J Roentgenol. 2020: 215(1): 87-93, doi: 10.2214/AJR.20.23034, indexed in Pubmed: 32174129.

31. Pereira MR, Mohan S, Cohen DJ, et al. COVID-19 in solid organ transplant recipients: Initial report from the US epicenter. Am J Transplant. 2020; 20(7): 1800-1808, doi: 10.1111/ajt.15941, indexed in Pubmed 32330343.

32. Miesbach W, Makris M. COVID-19: coagulopathy, risk of thrombosis, and the rationale for anticoagulation. Clin Appl Thromb Hemost. 2020; 26: 1076029620938149 , doi: 10.1177/1076029620938149, indexed in Pubmed: 32677459

33. Coll E, Fernández-Ruiz M, Sánchez-Álvarez JE, et al. Spanish Group for the Study of COVID-19 in Transplant Recipients. COVID-19 in transplant recipients: The Spanish experience. Am J Transplant. 2021; 21(5): 1825-1837, doi: 10.1111/ajt.16369, indexed in Pubmed: 33098200.

34. Messika J, Eloy P, Roux A, et al. French Group of Lung Transplantation. COVID-19 in lung transplant recipients. Transplantation. 2021; 105(1): $177-$ 186, doi: 10.1097/TP.0000000000003508, indexed in Pubmed: 33141808

35. Picard C, Le Pavec J, Tissot A, et al. Groupe Transplantation Pulmonaire de la Société de Pneumologie de Langue Française SPLF, Groupe Transplantation Pulmonaire de la Société de Pneumologie de Langue Française SPLF. Impact of the Covid-19 pandemic and lung transplantation program in France. Respir Med Res. 2020; 78: 100758 , doi: 10.1016/i.resmer.2020.100758, indexed in Pubmed: 32474398.

36. Hardman G, Sutcliffe R, Hogg R, et al. NHS Blood, Transplant Cardiothoracic Advisory Group Clinical Audit Group. The impact of the SARS-CoV-2 pandemic and COVID-19 on lung transplantation in the UK: Lessons learned from the first wave. Clin Transplant. 2021; 35(3): e14210, doi: 10.1111/ctr.14210, indexed in Pubmed: 33368697 